\title{
Nuevos datos sobre el origen del reino de Navarra
}

\author{
Jose Maria Muruzabal Aguirre
}

\section{CRONISTAS E HISTORIADORES}

Desde las antiquisimas "Genealogías de Roda" hasta la "Crónica" de Avalos de la Piscina, la tradición historiográfica y cronística de Navarra ', e incluso la castellana, musulmana y franca. siempre se han interesado por los orígenes del reino pamplonés. En dos escuetos textos, la "Crónica Albeldense" "señala a Sancho Garcés I como el primer rey pamplonés. A su vez, el "Códice Rotense" parece senalar colectivamente como reyes a todos los caudillos pamploneses y francos ${ }^{3}$, frente a los aragoneses, pallareses, gascones y tolosanos, que sólo son condes; pero prestan las "Genealogias" una especial atención a Sancho Garcés I ". Este rey. muy poco despues, es designado como el primer rey de Pamplona en un vibrante texto que se encuentra parcialmente en la "Crónica Albeldense" ":

In era nongentesima cuadragesima tertia, surrexit in Pampilona rex nomine Sancio Garseanis. Fidei Christ inseparabiliterque venerantissimus fuit...

Oroastr cut Gross, C. "La memoria historica de Navarra a fines de la Edad Media: la historiogratia nacional:. Principe de Viana. Homenaje a Jose Mara Lacarra. 1986. tomo II. pp. 591. 606.

Item nomma pampilonensium regum. Additio de regibus pamplonensibus.

Ordo numerum regum Pamplonensium. De reges francorum

Sanzio Garseanis, obtime imperator, accepit uxor Tota Asnari et genuit Garsea rex et domma Onneca..

dommo Ysamo qui fuit captibus in Tutela et abstiaxi eum de ferros rex Sanzio Garseanis.

Sobre estos textos, ver las obras de Martin Duque J.A.: Gran Atlas de Navarra. Historia Pamplona. 1986.

"Algunas observaciones sobre el caracter originario de la monarquia pamplonesa" Homendje. a Jose Maria Lacarra II. Principe de Viana. 1986. p. 525-530. "Horizontes de ia investigación en Historia medieva! de Navarra». Primer Congreso General de Histoma de Navarra. Ponencias Pruncipe de Viana. 1986, p. 125-143. 
Contrariamente. los intelectuales musulmanes de la época dan la misma consideración al rey Sancho I y a los caudillos antecesores: éstos reciben el tratamiento de emir y Pamplona se presenta como una ciudad abiertamente enemiga del Islam, casi independiente".

Los diversos cronistas cristianos oscilan entre estas dos tendencias. Sampiro recuerda especialmente a Sancho Garcés 1; y la "Historia Silense", al hablar de los origenes del reino de Navarra, se fija en los Jimenos, los Sanchos, a los que enlaza nada menos que con el duque Pedro de Cantabria ". Sin embargo, la "Crónica Najerense". al describir los antecedentes familiares de Sancho el Mayor ", cita a Iñigo Arista: Rodrigo Jiménez de Rada, en su "Historia de los hechos de España", califica a Garcia Iñiguez de rey ": finalmente, la "Crónica de los Reyes de Navarra", del Principe de Viana. describe abiertamente la elección de Inigo Arista como la del primer rey de Navarra ": como igualmente hará García de Eugui. También es de señalar que, desde la "Crónica Najerense", los primitivos tiempos de Pamplona se tratan frecuentemente con total imprecisión y se confunden y mezclan unos personajes con otros.

Desde que el Padre Moret, historiador jesuita del siglo X.VII. hablase en sus "Anales" de la lucha de los montañeses como factor desencadenante de la formación del reino pamplonés, se ha hecho un tópico tal idea: pero falta explicar, en tal caso. por que otros núcleos de resistencia antiislámica no devinieron en reinos, siendo tan prestigiosos o más que la modesta ciudad de Pamplona. Y así, pasando a nuestro siglo, José María Lacarra ve el reino pamplonés como una formacion pirenaico-vascona ${ }^{1 ?}$.

- En este ano fue la campana del hayib Abd al Karim ibn Abd al-Wahid ibn Mugit con la acei fa contra el enemigo de Dios Balask al Yalasqi. señor de Pamplona... Para oponerse a las algaras de su caballeria salieron Musa ibn Musa y su aliado Garsiya ibn Waannago. emir de los Baskunis.. "E. LEVI-PROVENÇAL y E. GARCIA GOMEZ. "Textos ineditos del Muqtabis de Ibn Hayyan sobre los origenes del reino de Pamplona". Al Andalus. 19. 1954. p. 295-315

Interea nunci venerunt ex parte regis Garsiani. "It illuc pergeret rex noster suprafatus, ad debellandas ubes perfidorum.

Sed Garsias, qui ex nobil Petri Cantabriensium ducis origme ducebatur. postquam declaratur rex. et barbaris armatus crebo occurreret et eorum inpetus, ne in fines christianorum solito more desevirent instanter conpescere cepit

In primis ergo sciendum quod Semeno genuit Garsiam Xemenit et Ennecum Xemenit Garchas Sement genut Santium Garciet, qui cognommatus est Avarca. Santhus Garciet ex domna Tolal regina bisnepta de Eneco Aristra. genuit regem Garciam. qui cognominatus est Trenulosus

Al morir su madre lo adoptó un noble que habia sido estrecho colaborador del rey Garcia desde los tiempos de lingo Arista.

$Y$ este rey D. Inigo Ariesta trujo por armas un escudo colorado. sembrado de ariestas ardientes...

"Del sigio VIII al X los vascones de la tierra de Pamplona pasan de mantener una actitud defensiva - y aun de convivencia con el Islam - a la de Reconquista de territorios para la 
afirmación un tanto arriesgada y que venía siendo defendida desde el siglo $X \mid X$, de forma mucho más radical y obsesiva por diversas formaciones vasquistas, con Arturo Campion a la cabeza. El vasquismo, atenuado o radical, choca con la evidencia de la amplia romanización del Pirineo occidental y alto Valle del Ebro que se puede comprobar con una visita al Museo de Navarra. y los diversos testimonıos del pasado, arqueológicos y documentales. Desde el siglo I a.C. Ias tribus vasconas se verán ante la tiránica cultura romana y dejarán de evolucionar autónomamente ante los nuevos horizontes y perspectivas. Es algo muy común en la Historia. También cambió el mundo mediterráneo con las invasiones germanas o musulmanas, y América con el descubrimiento colombino; Europa se transformó con la ciencia experimental en el Siglo de las luces y el Imperio español declinó con la llegada del Liberalismo racionalista. la Revolución industrial, y la secularización de las costumbres. Efectivamente. Roma aportó derecho, organización política y militar, arquitectura, ingeniería. arte, literatura, economía, comercio, religión... y es imposible que tras 800 años de presencia romana y goda, a la vista de árabes y francos y con la presencia cristiana, las tribus vasconas olvidasen todos sus conocimientos y experiencias vitales, se extinguiesen los hombres no autóctonos, y recomenzase la época bruscamente cerrada con la llegada de los legionarios romanos. Si en el siglo I no habia elementos culturales propios que fuesen suficientes para formar un estado sofisticado, menos aún en los siglos VIII-IX. Antes bien, son los diversos sustratos etnicos y culturales los que entrarán en juego para formar el nuevo reino de Pamplona.

Claudio Sánchez Albornoz reacciona contra el vasquismo radical en su conocida y documentada obra "Origenes del Reino de Pamplona. Su vinculación con el valle del Ebro». El insigne historiador considera como

Cristiandad. Este cambio de actitud hay que ponerlo en relacion con la evolucion politica de los territorios colindantes: recesion en el Imperio carolingio. mayor presión del emirato y califato sobre el valle del Ebro. avance de la monarquia asturiana en colaboración con la de Pamplona.

Consecuencia de las presiones que vienen del sur y del impetu reconquistador sera la fijacion. primero. de unas fronteras defensivas entre vascones y musulmanes; después. el avance hacia el valle del Ebro y la incorporación de tierras que ya no formaban parte del solar tradicional de los vascones. Con ello el elemento humano que integra la nueva monarquia será también distinto. Los diversos grupos de gentes que en un principio mantenian la resistencia en los valies pirenaicos. parecen ahora reunidos en torno a una monarquia única. que dirige la lucha ante la presión creciente de los ultimos dias del califato... El nucleo originario del reino lo forman gentes del estirpe vasca. que habitan los distintos valles que van desde Roncal y Sangüesa hasta Berrueza y Alava. Pamplona habia perdido su condicion de centro urbano director. con una poblacion etnica y culturalmente diferenciada, que tuvo en siglos anteriores: Io urbano ha quedado disuelto en lo rural y tribal vasco, que predomina por todas partes". LAC.ARfA. J.M.. "Historia del Reino de Navarra en la Edad Media". Editorial Aranzadi. 1975. 
primer rey pamplonés a Iñigo Arista y nos describe pormenorizadamente las interioridades familiares de los principales protagonistas, pero olvida determinar los factores intelectuales y juridicos que dan lugar a un título de rey, categoría sacia y casi sacramental para la época. J. Angel Martín Duque ${ }^{13}$ ha rescatado el valor de los antiguos códices del siglo $X$ y señalado el entronque del reino pamplonés con la fenecida monarquia hispanogoda y los parámetros intelectuales y morales del cristianismo tradicional; y asi mismo determinado a Sancho Garcés I como primer rey de Pamplona. Sin embargo, parece que tales planteamientos debían llevar a una fusión con el reino astur, y no sólo a una fraternitas de reinos cristianos. Si el reino de Pamplona se declara sucesor de los reyes godos ¿cómo es que no se ensambla y une al más inmediato y legítimo continuador, el reino fundado por el noble visigodo Don Pelayo? ¿Y por qué alcanza Navarra la categoria sacra de reino, y no asi Alava. o Sobrarbe, o Ribagorza?.

Cuando se habla del origen del reino de Navarra se suelen comentar cosas distintas. Unas veces trata de determinarse los primeros caudillos resistentes al Islam. su estirpe y secretos familires. Otras se busca precisar quien alcanza la categoria regia, pues sabemos de caudillos pamploneses a la vez rebeldes y tributarios de Córdoba que han de soportar una guarnición de muslimes en la ciudad. También se buscan los aspectos procedimentales y jurídicos capaces de plasmar y formar una realeza. Las más de las veces se recurre a la lucha contra el invasor musulmán, pero la caida de los hispanogodos y la posterior reconquista es una condictio sine qua non, más que causa concreta de formación de un reino.

\section{UN TEXTO NARRATIVO SOBRE EL COMIENZO DE LA RECONQUISTA}

En el Catálogo de la Orden de San Juan en Navarra. Dona Consuelo Gutiérrez del Arroyo ${ }^{14}$ hace las siguientes explicaciones del documento catalogado con el número 4.477: “Papel 24 fols. Castellano, gótica libraria. Se añaden notas curiosas: una carta anónima que se repite varias veces y unas notas sobre la invasión árabe y el comienzo de la reconquista en Navarra".

El profesor Martin Duque ha hecho novedosas explicaciones sobre los códices Vigilano y Albeldense. las cuales recoge Eloisa Ramirez Vaquero en la Historia de Navarra. Temas de Navarra-1. Kriselu. Pamplona. 1990. Tambien yo aludi a tales explicaciones en mi articulo ".El emblema de Navarra". Espacio. Tiempo y Forma. Serie VII. t. 6. 1993. pp. 117-148.

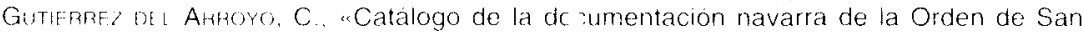
Juan de Jerusalen en el Archivo Historico Nacional. Siglos XII-X|X". Institucion Principe de Viana. 1992. 
Se trata de un documento, con fecha de 1498, en el que se describen los bienes que el gran prior de la Orden de San Juan en Navarra tiene en Tudela y Arguedas. Que es un texto típicamente navarro lo vernos no solo en el ámbito en el que se encuentra, la documentación navarra de la Orden de San Juan. sino también en la designación de miramolin a un caudillo musulmán y en la especial atención en hablar del rey Enequot. También debe atenderse la sugerencia de que la vencida monarquia goda tiene su continuación en la resistencia montañesa, pues en el ámbito cantábrico como en el pirenáico se habla de Espayna. Intentaré una transcripción del texto:

En el nombre de Jesucristo quisies Señor nuestro. Aquí comiença el libro del primer fuero que fu trovado en el salvamento de Espayna como ganaron enpecamos los montayneses la tiera sinez este libro sines pora sienpre.

E quando los moros conquistaron Espayna por la racion que el Rey Rodrigo fillo del Rey Voatitanus fizo al conde don Julian su sobrino que se iazio con su mujer. Ovo lo enviado a su sobrino a los moros e despues por la gran onta e pesar que ovo el conte don Julian: ovo fabla con el miramolin Rey de Marruecos e con Avusura e con Avaaliz e con otros reyes de moros e fizolos e por la vatalla el Rey Rodrigo eritre entre Murtia e Lorca en el campo que dize de Sant Cristoval e ovo grai matanca de cristianos y perdiose el Rey Rodrigo a tiempo fu trobado el cuerpo e era insepulto en Portugal en que avie estato que alli iazia el rrey Rodrigo. Entonces se pierde Espanya ata los puertos sino en Gaiacia a las Asturias que daqua Vizquaia de las tierras vaxas.

Fue rey Enequot e faga cort por Gracia vien establido por fuero en Espanya pora sienpre por Muyl rey que después sería no les pudiesen ser malo pues totella co es pueblo que lo abitaban.

\section{EL FEUDALISMO, CLAVE DEL ORIGEN DEL REINO DE NAVARRA}

Desde que los revolucionarios franceses comenzaron a hablar sobre el Feudalismo, una enorme bibliografía se ha desarrollado tratando de aclarar sus origenes y principios, la razón de su ser y de su funcionamiento. Y las opiniones han sido de lo más variopintas. Desde quienes lo extienden a toda la Europa medieval, hasta quienes lo restringen a las tierras del Loira al Rhin; desde quienes lo consideran como una manera especifica de tener o usufructuar tierras, hasta quienes se fijan en las estructuras de poder y reclaman, en el ámbito de los pactos privados de fidelidad, propiedad y hereditariedad de tierras, ejercicio delegado de funciones regias, y hasta apropiación de estas funciones o potestas regia. Veamos una posible definición del Feudalismo.

Fue el Feudalismo un sistema político, económico y social, propio de la Edad Media europea, heredero del Derecho romano y las costumbres 
germanas, influenciado por el Cristianismo, que se caracterizó por el mando supremo de un rey de derecho divino y el refuerzo del poder público mediante relaciones vasallático-dominicales o vínculos de fidelidad personal, distorsionadores de las jerarquias de mando. Efectivamente, el Derecho romano, en sentido amplio, tanto el privado como las instituciones políticas, están en la base de la cultura altomedieval. Términos como imperio, realeza, comités, comitatus, servus, stipendium, precarium, etc., están entre las expresiones usuales del momento. Reflejo de la Romanidad y de la autoridad imperial aceptada en el "Nuevo Testamento", tiene diversos significados el imperium altomedieval hispano: Universidad cristiana bajo el sacro emperador romano; caudillaje y tutela sobre varios reyes y territorios cristianos, al modo como se habia dividido en tiempos el Imperio romano; y simple mando efectivo y brillante. En el Bajo Imperio romano encontramos ya el colonato, campesinos agobiados por impuestos y deudas que se entregan al patrocinio de un terrateniente y que terminan por quedar adscritos a la tierra. Asi mismo aparece el comitatus o grupo reducido de guerreros que acompañan al emperador en los numerosos conflictos fronterizos. $Y$ hasta tropas privadas, buccellarii, que prestan servicios a personalidades de importancia, en cualquier región del Imperio. También los germanos tenían una especie de comitatus o grupo de guerreros libres, comprometidos voluntariamente a servir y combatir con un jefe.

El Cristianismo dio el necesario soporte moral al mundo medieval. La autoridad publica es querida por Dios, pero no para comportarse arbitrariamente. sino para servir al bien común. La idea de rey es tributaria de las ideas cristianas y de la Romanidad. Para la República romana, la realeza sugeria la idea de opresión y tiranía. Los reyes normalmente eran gobernantes plenamente independientes, pero con el tiempo serán también caudillos asociados y sometidos a Roma. En el "Nuevo Testamento", por ejemplo, podemos ver a reyes como Heródes el Grande y Heródes Antipas o Agripa. completamente sometidos a la superior autoridad romana. Esta idea es operativa en la Alta Edad Media, y también en las relaciones regioimperiales, pero el Cristianismo centrará primordialmente la idea de rey en la imiagen de los reyes de Israel, elegidos por Dios para dirigir al pueblo e intermediarios entre Dios y los hombres para asuntos terrenos.

Singular aspecto del Feudalismo son las fidelidades personales para reforzar el poder público. El vasallo presta homenaje a su señor, el rey ofrece un beneficio, de contenido muy diverso según lugares y épocas: puede ser dinero, rentas de la tierra, tierras en propiedad y por tanto transmisibles en herencia, ejercicio delegado de las tunciones regias en un determinado lugar que en los casos más extremos pueden hacerse hereditarias y devenir en un típico feudo. No debe reputarse, como hacen algunos autores, el último caso como único feudalismo auténtico. 
La fidelidad personal se desarrolla inicialmente entre los guerreros acompañantes del rey y los delegados regios en diversas civitates. El esquema típico de noble-guerrero será el del propietario de tierras y rentas suficientes para poder dedicarse a obligaciones militares, o el que las recibe, como beneficio, del rey. Fácilmente un propietario de una villa recibirá la delegación de funciones regias y también podrá enfeudar parte de sus tierras y tener caballeros a su servicio.

La interferencia de los acuerdos privados de fidelidad en las relaciones públicas de mando-obediencia causaron singulares efectos y distorsiones. El rey puede reforzar su presencia en los territorios mediante sus hijos (régulos) que en ciertos casos pueden llegar a ser reyes: un rey someterá con dificultad su auctóritas a otro, caso de deberle vasallaje por un título nobiliario: los nobles brindan al rey auxillum et consilium, pero pueden exigir cuentas e intervención en el mando, por su pacto vasallático, como lo vemos en las confirmationes de los documeritos medievales, que se refieren a actio como las testificaciones a la conscriptio: los matrimonios pueden enredar las fidelidades hasta ser un señor vasallo de si mismo, o deberse mutuamente fidelidad. dos nobles.

El reino de Navarra fue, a su manera. un reino feudal, presidido por relaciones de fidelidad personal. Hechos como la sucesión de Sancho el Mayor, formación del condado de Navarra, restauración de Sancho Ramirez o la proliferación de honores y tenencias son fenómenos tipicamente feudales: y también el origen y formación del reino, como veremos más adelante. Los conceptos de rey, de su autoridad y deberes. en el reino pamplonés, son igualmente tributarios de los sustratos culturales altomedievales.

\section{EL REINO DE PAMPLONA Y LA VISION PROVIDENCIALISTA DE LA HISTORIA}

Hemos visto a Iñigo Arista con el apelatıvo de rey. Pero tal término es de contenido impreciso, altomedieval; se trata de un rey sin plena soberania, caudillo de un pueblo, como lo fueron también los primeros reyes visigodos, federados a Roma, y ciertos reyes del "Nuevo Testamento". Sancho Garcés I responde a otro modelo de realeza; es el concepto normal, que conoció el mundo romano, de rey como gobernante absoluto e independiente, el modelo de los reyes visigodos aureolados con todos los atributos de la realeza, la imagen de los reyes de Israel, elegidos por Dios para gobernar al pueblo según la Ley divina y dirigirlo en las luchas contra sus enemigos. Veamos algunos datos. 
El texto navarro transcrito, sanjuanista, ya nos indica que los montañeses buscaban salvar la pérdida España de los reyes visigodos, una España cristiana sometida por los musulmanes y su miramolin. En su articulo mío titulado "El emblema de Navarra" y publicado en la revista "Espacio, Tiempo y Forma" señalé que el debatido árbol de Sobrarde. acuñado en las primeras monedas navarras ${ }^{1 ;}$, es el árbol de Jesé, simbolismo de los reyes de Israel y emblema representativo de una monarquía ideal, justiciera. benevolente con los oprimidos y ajustada a las leyes divinas. Este simbolo aparece ya en la primera moneda navarra, de Sancho Garcés I y con la leyenda NAIARA. Creo que es inapelablemente significativo que el primer rey "soberano" de Pamplona, según las Crónicas, utilice el simbolo del origen de los reyes de Israel y además utilizado por los reyes godos. Verdaderamente. Sancho I no es el simple caudilio de un pueblo, sino un rey según los patrones israelies y cristiano-godos.

La ceremonia del alzamiento en el escudo, de lejanos origenes germanos ${ }^{16}$. quizás fuese retrotraible a tiempos muy anteriores a Garcia Ramirez el Resaturador, y desde luego tiene también indudable sabor bíblico , teocrático y legitimador.

Ei verbo utilizado en los citados códices para explicar el comienzo del mandato del rey Sancho 1, surrexit, es ilustrativo. En los textos bíblicos hay muchas frases con la idea de levantamiento o alzamiento y se utilizan verbos como consurgere, exsurgere, elevare, levare, exaltare, erigere... Para designar el entronamiento de un rey israelí se usan expresiones

A. Ubie ro Artr.ta. "Sobre la conquista de la Rioja por los pamploneses". Homenaje a Jose Micarra. II. 1986. p. 755-763.

Sancha Alemornoz. C.. "La Ordinatio principis en la Espana goda y postvisigoda" en Estudios sobre las instituciones medievales españolas. Mexico. 1965.

$2 \mathrm{Sam}$ 22.3: "Mi Dios. lá roca en que me amparo. mi escudo. mi poder salvador. maccesible asilo

2.Sam 22.36: "Me entregaste tu escudo salvador y tu amabilidad me ha engrandecido".

Sal. 3.4: "Pero tu. ;oh Yahve!. eres escudo en torno mo. mi gloria, el que me hace erguir la cabezan,

Sal. 5.13: "Pues al justo, joh Yahvé!, tú le bendices y le rodeas de tu benevolencia como un escuciom.

Sal. 17.3: "Yavé es mi roca. mi ciudadela. mi libertador: mi Dios, mi roca a quien me acojo: mi escudo. mi fuerza salvadora. mi asilo"

Sal. 26.5: "Pues El me pondrá en seguro en su tienda el dia de la desventura. me tendra a cu bierto en su pabellón. me pondrá en alto sobre su rocan.

Sal. 83.10: "Escudo nuestro. Dios, mira y contemplas el rostro de tu ungido".

Sal. 90, 4-12: "... te cubrira con sus plumas, hallaras seguro bajo sus alas, y su fidelidad te será escudo y adarga... y ellos te levantarán en sus palıias. para que tus pies no tropiecen en las piedras..

15. 21.5: "AArriba, principes, engrasar el escudo"». 
como coepere regnare, constituere regem, exaltare regem, confirmare regem. ungere... y en el caso de los reyes helenicos se describen ceremoniales regios como ceñir corona. imponer diadema, tomar cetro... La expresion surrexit. del verbo surgere. también se utiliza. Referida a Abraham, Isaac. Jacob o Josué la podemos encontrar; aunque también en circunstancias más comunes. En Deuteronomio 13. 1 se habla de un falso profeta que se alza anunciando prodigios y ensalzando los idolos. En Nehemias 9. 4 los levitas se alzan en sus gradas clamando a Dios y arrastrando al puebio a volver a la alianza con Yahvé. El capítulo 33 del primer libro de los Macabeos muestra a Anticco Eupator levantándose de madrugada para dirigir su poderoso ejército contra Judá. Finalmente, y esto es lo más significativo, Saúl se alzó. surrexit, de su descanso para ser ungido por Samuel como primer rey de Israel ${ }^{1}$. Vemos que la expresión surrexit tiene frecuentemente un significado especial en la Vulgata: es un levantarse singular, desde la postración o el sueño, y a veces poi orden divina. En las crónicas ovetenses, se describe la toma del poder por los reyes visigodos y astures como comenzar a reinar, reinar, ser ungidos, tomar el cetro o el trono... Para el caso de Sancho Garcés I no se litiliza nada de eso, solamente se describe su acceso a la realeza con una terminología y como un hecho equivalente al del rey Saúl. $Y$ como el israeli fue un gran guerrero (1 Sam. 10,1: “Tú reinarás sobre el pueblo de Yavé y le salvarás de la mano de los enemigos que le rodean»), tambien el rey pamplonés lo es («... piadoso con todos los fieles y misericorde con los católicos oprimidos... mag. nifico guerrero contra las gentes de los ismaelitas...").

Este rey pamplonés conquistó diversos territorios. En un mapa podriamos ver que sólo avanza al amparo de los Pirineos o, al Occidente de Pamplona, con los montes vascos y los ejércitos astures a retaguardia. Conquistó Nájera ${ }^{19}$, a la que el “Códice Rotense» califica de urbs, no de civitas ni de terra. Si los lazos familiares unian a los cabecillas de Nájera y Pamplona o solamente representaba una deseable y feraz tierra riojana.

No comparto la idea de C. Sanchez Albornoz sobre la legitimidad de Don Pelayo como procedente de la elección nobiliaria, al modo visıgodo. En las cronicas oventeses os todo el puebio el que lo proclama. al igual que en e! A.T. el pueblo judio pie a Yave un rey que les conduzca a los combates y les gobierne 1 Sam. 10, 17-20: "Samuel convoco al pueblo ante Yave on Mastá y dijo a los hijos de Israel... Presentaos ahora ante Yave por tribus y por familias. Samuel hizo que se acercasen todas las tribus de Israel..." 1 Sam. 12.1: "Dijo Samuel a todo Israel. Ya veis que os he oido en cuanto me habeis dicho y que he puesto sobre vosotros un rey" Cronica de Altonso lll: "Y el. dirigiendose a las tierras montanosas. reunio a cuantos hallo que iban a concejo... Una vez que el hizo correr sus ordenes por entre todos los astures. se reunieron y eligieron a Pelayo como su princope.

V. nota 15 
no lo sabemos. Pero es ilustrativo su apelativo de urbs. En la Vulgata no hay gran diferencia entre los términos civitas y urbs. si bien el primero es mucho más empleado que el segundo. Pero en la literatura clásica urbs es el apelativo de Rorna. y en el "Códice de Roda". en la "Crónica de Alfonso III", urbs es sinónimo de capitalidad y se discierne de civitas con matemática precisión. Así, para los tiempos hispano-visigodos, se califica a Toledo de urbs y de civitas a Nimes. Tuy y Córdoba. Pero una vez que se ha producido la invasión musulmana, Córdoba, capital del emirato. se califica de ciudad patricia y urbs. Toledo pierde ese rango y se le llama solamente civitas, como también a Lugo. Tuy, Oporto. Braga. Viseo. Zamora, Leon. Sevilla. Gijón. Astorga, Zaragoza. Tudela y Huesca "En nuestro caso, Najera es urbs, capital. capital política y regia, y asi se manifiesta en las primeras monedas del reino, que tienen la leyenda de NAIARA. y no de PAMPILONA. Si Pamplona es relegada, pienso que puede ser por considerarla como ciudad sacra, episcopal; y pretender establecer, ritualmente. la capital regia en una ciudad conquistada, como David ocupó Jersualén para capital de su reino; asegurando nuevos territorios al adelantar la urbs capitalina.

Pero no podía olvidarse a Pamplona en el "Codice Rotense". En el capitulo titulado "De laude Pampilone epistola", a la famosa carta del emperador Honorio le sigue una hermosa alabanza de Pamplona, que tiene indudables referencias biblicas. Pamplona se presenta veladamente como imagen de la ciudad santa de Jerusalén, la Jerusalén restaurada de los profetas y especialmente la del Apocalipsis de San Juan. Es un lugar sagrado hecho por Dios, generoso en frutos y de vida amable. como en el Paraíso terrenal. Su solera está atestiguada por las reliquias de los mártires y es tan venerable como Roma. No creo que fuese escrita en tiempos hispano-godos, como dice Lacarra, sino expresamente para los tiempos del alzamiento de la monarquia pamplonesa, pues encaja perfectamente en todo el esfuerzo legitimador de la realeza y del nuevo reino. que estamos viendo. Si en una frase se habla de resistir a los vascones, no es porque éstos asediasen la ciudad". Antes bien, toda la frase es de carácter religioso y habla de "apartarse de los herejes» y de resistir a los "vascones", a los que se supone como gentes desconocedoras del latin. dificiles de predicar en lengua sagrada, y hasta faltos del

No courre esto con el Codice Abeldense. al que considero mucho menos tecnico que el Roterse. si bien sobresale por sus aspectos artisticos.

Aqui. Lacarra hace una equivocada miterpretacion de la bagauda y de los excedentes de poblacion montanesa que orgina. en la epoca tenomems de bandiaje. 
bautismo y sacramentos. En el texto se emplea un latin desastroso, pero intentaré una traducción muy libre, señalando posibles correspondencias con la Biblia. aunque con seguridad podrán encontrarse más.

Este lugar propicio. creado por Dios y hallado por el hombre. ha sido senalado por Dios alli para que consideréis todos los dias del ano el valor del descubrimiento. Que se encuentre encaminado en cada momento hacia la riqueza. que en ningún caso sea empujado de la abundancia a la miseria. por ninguna desgracia. para que los bienes propios cubran todas las escaseces ".

Se alza majestuoso este lugar cuyas murallas tienen torres de 63 pies de anchura y 84 pies de altura: y el perimetro de la ciudad alcanza las 1.000 diestras. El número de las torres es de 67

A esta ciudad. Dios. por su misericordia. concedio el tesoro de las reliquias de innumerables martires. con cuyas oraciones es conservada salva entre gentes hostiles y barbaras, y con cuyos cuidados. por los muchos méritos de los martires, brilla la luz de los ángeles segun se dice alegóricamente desde antiguo $\cdots$. Si los hombres callasen para olvido de los mártires.

Gen. 1.1: "Al principio creo Dios los clelos y la tlerra.

Gen 2.4: "Este tue el origen de los cielos y la tierra cuando fueron creados. Al tiempo de hacer Yave Dios la tierra y los cielos, no habia aun arbusto alguno...".

Gen. 2.9: Hizo Yave Dios brotar en el toda clase ve árboles hemosos a la vista y sabros al paladar

Neh. 9.6: Tu. ¡Oh Yave! eres unico: Tu hiciste los cielos y los cielos de los cielos y toda su milicia: la tierra y cuanto hay en ella..."

Jn. 1.3 "Todas las cosas fueron hechas por El y sin El no se hizo nada de ouanto ha sido necho:

Is 60.5. "Entonces miraras y resplandeceras. palpitara y se ensanchara tu corazon. pues vendrati a ti los tesoros del mar. llegaran a ti las riquezas de los pueblos".

Sai. 47.3: "Bello promontoro alegra de toda la tierra el monte de Sion cn los confines del aquiton. es la ciudad del gran Rey".

1 Re 3.1: "Trajola a la ciudad de David hasta acabar de edificar su casa la casa de Yave y las murallas de Jerusalén en derredor.

Sal. 47. 13-14: "Dad vueltas a Sion. girad en torno: contad sus torres. Poned atencion a sus murallas. considerad sus alcazares. para poder contarlo a las generaciones venderis:

Neh. 6. 15-15: "la muralla quedo terminada ol dia venticinco del mes de Elul... teniendo que reconocer que la obra se habia llevado a cábo por la voluntad de Dios.

Neh. 12.27: "Para la dedicacion de la muralla de Jerusalen fueron Hamados los levias do todos sus lugares, para venir a Jerusalen..."

1 Mac 13.33: "Simon edifico las fortalezas de Judea, las rodeo de altas torres y muros fuertes les puso puertas y cerrojos y las proveyo de vituallas"

is. 60.18: "No se hablará ya mas de violencia en tu tierra. de saqueo y de ruina en tu territorio Tus inuros los llamaras salvacion y a tus puertas alabanza"

Ap 21.12. Tenia un muro grande y alto y doce puertas... La ciudad estaba asentada sobre una base cuadrangular y su longitud era tanta como su anchura Midio con la cana la ciudad y tena doce mil estadios".

Is. 60. 1-2, "Levántate y resplandece. pues ha llegado tu luz. y la gloria de Yave alborea sobre ti. pues he aqui que esta cubierta de tinieblas la tierra y de oscuridad los pueblos. Sobre ti viene la aurora de Yave y en li se manifiesta su glora Las gentes andaran en tu luz. y los reyes a la claridad de tu aurora». 
las piedras proclamarian su recuerdo $y$ adornado por las virtudes

Pamplona. residencia para los justos Este lugar es siempre vencedor esta iene colocadas tres puertas y 4 postigos está delimitada por tres ángulos. - Es apta como refugio. Se dice en griego Pamplona. en latin puerta de todos. Omito las flores de los árboles ". un rio serpenteante desde el Oriente " se aleja hacia el Occidente. ya entre las aldeas proximas, ya por los alrededores llanos y sulitarios.

Apartese de los herejes: resistase. contraria. a los vascones Perpeluamente se le debe amar para que nadie se encuentre ser tenido por enemigo. Como la opulenta Roma ha sido salvaguarda por los romanos. Pamplona no ha dejado de estar alzada para los suyos. Esta maravillosa y gran región es tructifera "entre otras regiones. pues aqui. con el trabajo de

Is. $60.1920 \ldots$.Ya no sera el sol tu lumbrera de dia ni te alumbrara el resplandor de la luna. sino que Yavé sera tu eterna lumbrera. y tu Dios sera tu esplendor. Tu sol no se pondra jamas ni menguara tu luna porque sera Yave tu eterna luz:.

Ap. 21.23: "La cludad no habia menester de sol n de luna que la iluminasen. porque la gloria de Dios la iluminaba:

Siguiendo a Madoz. Lacarra senala el paralelismo de esta trase con Lc. 19.40

Muchos textos de la Biblia exaltan las virtudes y las asocian a la seguridad y salvacion en Dios

Sal. 36.29: "Los justos poseeran la tierra y moraran en ella por siempre"

Sal. 121, 6-8: "RRogad por la paz de Jerusalen! ;ivan seguros los que te aman! iReine la seguridad dentro de tus muros. Ia tranquilidad en tus torres Por amor de mis hermanos y compa. neros te dre: La paz contigo!

Sal. 124. 3-4: "De cierto no permanecera el cetro de los impios sobre el lote de los justos. para que no tiendan los justos sus manos a la iniquidad. Colma. joh Yave!. de bienes a tos buenos. a los rectos de corazon

15. 52.1: "Levantate, levantate, revistete de tu fortaleza. joh Sion! viste tus bellas vestiduras. Jerusatén. ciudad santa. que ya no volvera a entrar en in incircunciso mi inmundo".

is, 60.21: "Tu pueblo será un pueblo de justos. poseerá la tierra para siempre renuevos del piantio de Yave".

IS. 61.3: "Se les Hamara terebintos de justicia, plantacion e Yave para su gloria".

Ap. 2.1.27: tn ella no entrara cosa impura n quien cometa abominacion y mentira. sino los que estan escrios en el libro de la vida del Cordero».

Ap. 21.16: "La ciudad estaba asentada sobre una base cuadrangular y su longitud era tanta como su anchurax.

Toda ia literatura latina esta llena de ejemplos del lugar paradisiaco. el locus amoenus

Gen. 2.4: "Salia de Eden un río que regaba el jardin y de alli se partia en cuatro brazos".

Sal. 45.5: "Un rio con sus brazos alegra la ciudad de Dios. el santuano donde mora el intusimo».

Ez. 47.1: .... al oriente brotaban aguas. pues la tachada del templo estaba al oriente. y las ag: das descendian..."

Zaz. 14.8: "En ese dia manarán de Jerusalén aguas vivas. la mitad hacia el amor oriental y la otra mitad hacia el occidentals.

Ap. 22. 1: "Y me mostro un rio de agua de vida. clara como el cristat. que salıa del trono de Dios y del Cordero"

Ez. 34. 26-27: "Hare de ellas y de los alrededores de mi collado una bendicion. Mandare a su tiempo las lluvias. Iluvias de bendicion. Daran sus frutos los arbotes del campo. y la tierra lo suyos Habitarán en su tierra en seguridad. y sabran que yo soy Yave cuando rompa las coyundas de su yugo y las arranque de las manos de los que los osclavizaron 
rastrillos y con canales. se reconducen las aguas desde los rios a tierra abierta. Como los montes rodean la ciudad. Dios protege al pueblo. ahora y por siempre ". Amen.

Las Genealogías de Roda hemos de entenderlas no como un frio texto historiográfico sino a la luz del tono laudatorio y ensalzador de los caudillos de Pamplona. No importa que en ellas haya imprecisiones; tratan de garantizar y certificar, al modo biblico, la alcurnia y personalidad de los reyes, hombres bien incardinados en la tierra y tallados por su historia familiar para mandar sobre el pueblo. conducidos al poder por la providencia divina. No son unos simples advenedizos. Efectivamente. Adán y Cristo son los personajes con máxima identificación en los dos Testamentos por su inmediata filiación divina: pero hay muchos otros ejemplos en la Biblia de desarrollos genealógicos, tan queridos por el gusto oriental: Seth y su descendencia, hijos y descendientes de Noe. genealogia de Abraham, descendencia de Ismael, descendencia de Esaú. genealogía de Moisés y Arón. censos de tribus, ascendientes de Saúl, grupos de genealogias en el primer libro de Paralipómenos asi como descripciones familiares. genealogia de Esdras y de sus compañeros. genealogia de Tobías y de Judit, parentescos de los compañeros. genealogia de Tobias y de Judit, el epitalamio de la reina Leodegundia tiene concomitancias con imágenes biblicas y los textos históricos de los Códices Rotense y Albeidense. junto a las microcrónicas navarras que contienen. deben injertarse en la gran tradición cristiana de la interpretación providencialista de la Historia cuyo punto de partida es la Biblia. ¿Acaso las crónicas ovetenses no están también llenas de citas bíblicas? Muy descriptivo resulta la profecia de Gog y Magog, y el apelativo de agarenos o ismaelitas ${ }^{35}$ para con los invasores islámicos

Todo lo que nos presentan los Códices Vigilano y Rotense es un inmenso esfuerzo intelectual, juridico, histórico y literario, por demostrar y afianzar la

Senala Lacarra el paralelismo de esta trase con Sal. 124,2

Gat. 4. 21-31: "Decidme: los que quereis someteros a ha Ley. ¿no habeis oido la Ley?

Porque está escrito que Abrahan tuvo dos hijos. uno de la sierva v otro de la libre. Pero el de la sierva nacio segun la carne. el de la libre, en virtud de ta promesa. Lo cual tiene un sentido alegorico. Esas dos mujeres son dos testamentos: el uno que procede del monte Siná. engendra para la servidumbre. Esta es Agar. El monte Sinai se halla en Arabia y corresponde a la Jerusalen acturt. que es en efecto esclava con sus hijos. Pero la Jerusáten de arriba es libre esa es mestra radire: pues esta escrito

Alegrate. esteril. que no pares: prorrumpe en gritos tu que no conoces los dolores dol parto. porque más seran los hijos de la abandonada que los hijos de la que tiene marido.

$Y$ vosotros. hermanos, sois hijos de ha promesa a la manera de isaac Mas asi como entomees ol nacido segun la carne perseguia al nacido segun el Espiritu. ası tambien ahora. Poro cave dice la Escritura?. Echa a la sierva y a su hijo. que no sera heredero el hijo de la esclava con el hijo de la libre En fin hermanos que no somos hijos de la esclava. smo de ta libro. 
legitimidad, alcurnia y solera del reino pamplonés y sus reyes, y apuntalar y remachar su categoría soberana y providencial, el cual se inicia con Sancho I. Los intelectuales eclesiásticos de la época debieron ver un paralelismo entre el pueblo de Israel que pide a Dios y elige un rey que les unifique en la lucha contra sus enemigos filisteos, y los hombres del Pirineo occidental. acosados por un torbellino de enemigos y necesitados de un guia frente al terrible enemigo religioso de Córdoba. $Y$ asi lo era realmente. Desde el Bajo Imperio romano hasta el siglo $X$, las tierras navarras constituyen un punto de fricción y conflictividad progresiva. A la bagauda de la época romana le sucede el desastre de las invasiones germanas y con la monarquia hispano goda se mezclan las dificultades económicas. las intromisiones militares y el feroz combate entre facciones nobiliarias godas. Por si ésto fuera poco, la invasión musulmana provoca un insólito cambio que agravará la situación en todos los órdenes y creará un vacio de poder. Asturias es débil y lejana, los francos no son aceptables para un pueblo con perspectivas hispanovisigodas. como lo son difícilmente para los gascones, los Banu Qasi sólo representan el dudoso parentesco de unos hombres pasados al Islam y de insegura colaboración. y Córdoba es un enemigo irreconciliable y mortal. Ante la imposibilidad de soluciones, los pamploneses y sus aliados reaccionan congregándose en torno a un rey guerrero que será legitimado. como nuevo Saúl. por la voluntad popular, por la necesidad de defensa, en todos los órdenes, del pueblo cristiano, y el favor divino a tan noble empresa.

\section{OTROS DATOS COMPLEMENTARIOS}

En la Hispania visigoda, el rey ocupaba la cúspide jerárquica. Su potestad se desplegaba en los distintos lugares del reino a través del escalón inmediatamente inferior que eran los condes (comes), gobernantes, jueces y guerreros que dirigian la vida de los condados (comitatus) ${ }^{36}$. Por lo menos habia tantos condados como ciudades episcopales, aunque sospecho que muchos emplazamientos que recibian el nombre de civitas podían acoger una residencia condal. Pamplona era una ciudad episcopal, y por tanto también lo sería condal. La existencia de una cierta tradición política, administrativa. documental y económica debió ser un factor importante cuando, desaparecida la autoridad toledana, los pamploneses se vieron abocados a desarrollar una vida política en solitario.

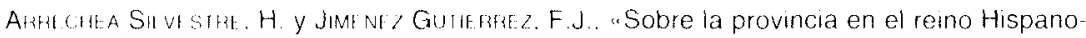
Visigodo de Toledo" en Concilio de Toledo. XIV Centenario. Toledo. 1991. 
Los diversos dialectos vascones constituian en los siglos IX y $X$ un medio de comunicación singularisimo, diferenciador e ininteligible por cualquiera de los sistemas lingüísticos que le rodeaban. Desde luego no se ceñian a los limites del reino pamplonés y hasta se proyectaría por tierras castellanas, pero tuvo que facilitar tanto la aglutinación interior como el rechazo a intromisiones extrañas.

El "Códice de Roda" describe magistralmente el recorrido seguido por Alfonso 1 el Católico en sus incursiones por territorio musulmán. La primera acción parte de Lugo y se interna hasta Viseu. Salamanca y Avila, para retroceder hasta Astorga. Coincidió con la momentánea debilidad musulmana en la zona durante los años 740-743. El general Balch y sus jinetes sirios fueron acorralados en Ceuta pos los bereberes en octubre del 740 . En España, los bereberes de Galicia y la cordillera cantábrica se suman a la revuelta y se dirigen a la capital andalusi, pero al fina son derrotados. En el año 743, el Gobernador de Africa impuso como vali de Al Andalus a Abuljatar quien mantuvo la paz hasta el 745. La segunda acción comienza en León. llega a Simancas, continúa por Saldaña, Amaya, Segovia y Osma, y se retira a Villafranca de montes de Oca. Alfonso I pudo buscar nuevas tierras de saqueo, al calor de la crisis de los años 745-747, cuando se disputan el poder Abuljatar, Thuwaba y Yusuf ben Abderramán el Fihrí. La tercera campaña parte de Veleya de Alava y Miranda de Ebro, recorriendo Abeica, Cenicero y Alesanco. Se produciría durante la crisis del 750-755, cuando una gran hambre se extiende por el valle del Ebro y posteriormente Zaragoza, acaudillada por Al-Sumail, es asediada por los yemenies. Aqui debieron comenzar las apetencias asturianas por la Rioja, cosa que no podia agradar a cordoberses, Banu Qasi, y de alguna manera. tampoco a la codicia de los impulsivos guerreros de Pamplona, cuyas relaciones con sus vecinos eran complejas y cambientes, en particular de amor-desconfianza hacia los astures. Así. Sancho I hará que Nájera sea formalmente su capital, ciudad davídica, centro de nuevos territorios a semejanza de Oviedo o León, y atalaya frente a apetencias extrañas. Es de pensar que la ambición de nuevos territorios contribuyó a fortalecer la tendencia a una monarquia diferenciada. 